\title{
Urinary excretion of total trichloro-compounds, trichloroethanol, and trichloroacetic acid as a measure of exposure to trichloroethylene and tetrachloroethylene
}

\author{
MASAYUKI IKEDA, HATSUE OHTSUJI, TOSHIKO IMAMURA, and \\ YOSHIHIKO KOMOIKE \\ Department of Public Health, Kyoto University Faculty of Medicine, Kyoto and \\ Institute of Industrial Health, Sumitomo Hospital, Osaka, Japan
}

Ikeda, M., Ohtsuji, H., Imamura, T., and Komoike, Y. (1972). Brit. J. industr. Med., 29, 328-333. Urinary excretion of total trichloro-compounds, trichloroethanol, and trichloroacetic acid as a measure of exposure to trichloroethylene and tetrachloroethylene. To investigate the relation between trichloroethylene and tetrachloroethylene concentrations in working environments and metabolite concentrations in urine, a series of surveys was conducted at 17 workshops where the vapour concentration in the air of each workshop was relatively constant. Urine samples collected from 85 male workers were analysed for total trichlorocompounds (TTC), and trichloroacetic acid (TCA). Trichloroethanol (TCE) was estimated by difference. Statistical analyses of the data revealed that the urinary concentrations of both TTC and TCE were proportional to the atmospheric concentration of trichloroethylene. The concentration of TCA was also related to the vapour concentration up to 50 p.p.m. but not at higher concentrations. Further calculations suggested that only one-third of the trichloroethylene absorbed through the lungs was excreted in the urine during working time.

In tetrachloroethylene exposure, urinary metabolite levels increased until the atmospheric concentration of the solvent reached 50 to 100 p.p.m., but little increase occurred at higher concentration. This observation was further confirmed by experimental exposure of rats. The toxicological significance of changes in the metabolism of the two solvents is discussed in relation to the possible necessity of reducing the threshold limit value from the current value of 100 p.p.m.

There are numerous reports (Browning, 1965; Smith, 1966) on the toxicity of trichloroethylene, and its metabolism in vivo (Soucěk and Vlachová, 1960; Bartonicěk, 1962; Stewart, Dodd, Gay, and Erley, 1970b; Ikeda, Ohtsuji, Kawai, and Kuniyoshi, 1971; Parkhouse, 1969; Malchy and Parkhouse, 1969; Daniel, 1963) as well as in vitro (Byington and Leibman, 1965; Cooper and Friedman, 1958; Friedman and Cooper, 1960) has been extensively studied. Papers on tetrachloroethylene metabolism have also appeared (Yllner, 1961; Daniel, 1963; Stewart, Baretta, Dodd, and Torkelson, 1970a). Nevertheless the relation between the intake and excretion of these solvents still requires investigation in human subjects exposed daily to these vapours in their working environments.

In the present investigation, an attempt was made to elucidate a quantitative relation between the atmospheric concentrations of trichloroethylene and tetrachloroethylene and the urinary concentra- 
tion of their respective metabolites by investigating selected workshops in which the vapour concentrations were relatively constant. The results presented here, together with those in a previous publication (Ikeda and Ohtsuji, 1969a), make it possible to estimate the average atmospheric concentration of the vapour of the solvent from the metabolite concentration in the urine of workers exposed to trichloroethylene or toluene, the two most popular solvents in industry.

\section{Materials and methods}

\section{Urine samples}

Surveys were conducted in the latter half of a week. Ten workshops using trichloroethylene (51 male workers) and seven workshops using tetrachloroethylene (34 male workers) in which the atmospheric concentration of the solvents were relatively constant were chosen. Urine samples were collected around $15.00 \mathrm{hr}$ after urine was excreted at about $13.00 \mathrm{hr}$.

\section{Urinalyses}

Determination of total trichloro-compounds (TTC), trichloroethanol (TCE), and trichloroacetic acid (TCA) (Tanaka and Ikeda, 1968) and creatinine (Ikeda and Ohtsuji, 1969b) were carried out. TCE was estimated by difference (Tanaka and Ikeda, 1968). In some instances, results were adjusted to the equivalent of a specific gravity of urine of 1.016 (Rainsford and Lloyd Davies, 1965) or expressed in terms of creatinine concentration (Jackson, 1966).

Determination of trichloroethylene and tetrachloroethylene in air

Air concentrations of these compounds were measured using Kitagawa (1961) detection tubes. At various sites in each workshop, at least five determinations were made; the average was taken to represent the environmental concentration.

\section{Statistical analyses}

The results of the analyses were assumed to be lognormally distributed (Heath, 1967). Regression lines were calculated by the least-squares method with weighting for the numbers of samples (Snedecor, 1956).

\section{Results}

Trichloroethylene exposure

Results from the workshop survey and urinalysis are summarized in the Table. The mean values of urinary metabolites were plotted against atmospheric concentrations of trichloroethylene (Fig. 1). The relationships for both TTC and TCE (Fig. 1A and D) appear to be well represented by straight regression lines of $Y_{1}=7 \cdot 25 X+5.5$ and $Y_{2}=5.57 X+$ $4 \cdot 4$, respectively, where $Y_{1}$ is TTC concentration in urine (mg/litre), $Y_{2}$ is TCE concentration in urine (mg/litre), and $X$ is trichloroethylene concentration in air (p.p.m.). Adjustment to a specific gravity of 1.016 (Fig. 1B) converts the former equation to $Y_{1}^{\prime}=4.97 \mathrm{X}+1.9\left(\mathrm{Y}_{1}^{\prime}: \mathrm{mg}\right.$ of TTC/litre of urine), and when the TTC concentration is divided by creatinine concentration (Fig. 1C), the equation is $\mathrm{Y}_{1}{ }^{\prime \prime}=5 \cdot 50 \mathrm{X}+6 \cdot 2\left(\mathrm{Y}_{1}{ }^{\prime \prime}: \mathrm{mg}\right.$ of TTC/g of creatinine). Standard deviations increased with the vapour concentrations in each case. The relationship in the case of TCA concentration (Fig. 1E) apparently deviates from the straight line of $Y_{3}=2 \cdot 74 X+$ $0.7\left(\mathrm{Y}_{3}: \mathrm{mg}\right.$ of TCA/litre of urine) when the vapour

TABLE

Metabolite Concentrations in Urine SAmples from Workers Exposed to Trichloroethylene at VARIOUS CONCENTRATIONS 1

\begin{tabular}{|c|c|c|c|c|c|c|c|}
\hline \multirow{2}{*}{$\begin{array}{l}\text { Trichloro- } \\
\text { ethylene } \\
\text { (p.p.m.) }\end{array}$} & \multirow{2}{*}{$\begin{array}{l}\text { Workshop } \\
\text { for }\end{array}$} & \multirow{2}{*}{$\begin{array}{l}\text { No. of } \\
\text { workers }\end{array}$} & \multicolumn{5}{|c|}{ Metabolite concentration ${ }^{2}$} \\
\hline & & & $T T C^{3}$ & $T C E^{3}$ & $T C A^{3}$ & $\operatorname{TTC}(1 \cdot 016)^{4}$ & TTC (creatinine) $)^{\mathrm{s}}$ \\
\hline $\begin{array}{r}0 \\
3 \\
5 \\
10 \\
25\end{array}$ & $\underset{\text { III }}{\text { II }}$ & $\begin{array}{c}366^{\circ} \\
9 \\
5 \\
6 \\
4\end{array}$ & 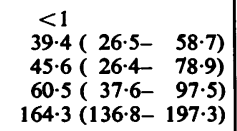 & 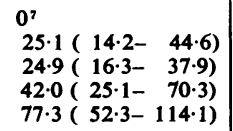 & $\begin{array}{l}<1 \\
12 \cdot 7(8 \cdot 8-18 \cdot 2) \\
20 \cdot 2(10 \cdot 0-40 \cdot 8) \\
17 \cdot 6(10 \cdot 3-30 \cdot 0) \\
77 \cdot 2(51 \cdot 6-115 \cdot 6)\end{array}$ & 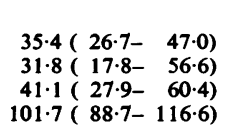 & 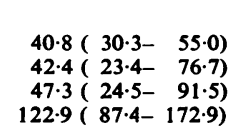 \\
\hline $\begin{array}{r}40 \\
45 \\
50 \\
60 \\
120 \\
175\end{array}$ & $\begin{array}{l}\text { II } \\
\text { II } \\
\text { IV } \\
\text { II } \\
\text { V } \\
\text { V }\end{array}$ & $\begin{array}{l}4 \\
5 \\
5 \\
5 \\
4 \\
4\end{array}$ & $\begin{array}{r}324.9(232.1-454.8) \\
399.0(287.6-553.5) \\
418.9(228.4-768.2) \\
468.0(347.9-629.6) \\
915.3(775.7-1079.9) \\
1210.9(790.7-1854.2)\end{array}$ & $\begin{array}{l}220.3(164.4-295 \cdot 3) \\
256 \cdot 7(202 \cdot 1-330 \cdot 8) \\
267.3(140.0-510 \cdot 3) \\
307.9(223.0-425 \cdot 6) \\
681 \cdot 8(581 \cdot 4-799 \cdot 5) \\
973.1(596.9-1586.4)\end{array}$ & $\begin{array}{r}90 \cdot 6(50 \cdot 2-163 \cdot 8) \\
138.4(83 \cdot 2-216 \cdot 5) \\
146.6(76 \cdot 3-281 \cdot 7) \\
155 \cdot 4(104 \cdot 3-231 \cdot 4) \\
230 \cdot 1(199 \cdot 0-267 \cdot 4) \\
235.8(187 \cdot 2-296 \cdot 9)\end{array}$ & $\begin{array}{l}204.4(156.8-266 \cdot 3) \\
253.3(194.8-329 \cdot 5) \\
257.8(154.6-429 \cdot 8) \\
308.9(228.8-417 \cdot 1) \\
481 \cdot 1(414.6-558 \cdot 3) \\
939 \cdot 1(770.6-1144.3)\end{array}$ & $\begin{array}{r}221.2(155.5-314.5) \\
337.7(267.8-425.7) \\
275.8(195.0-390.3) \\
359.0(223.7-576.1) \\
518.9(354.3-759.7) \\
1040.1(711.3-1520.9)\end{array}$ \\
\hline
\end{tabular}

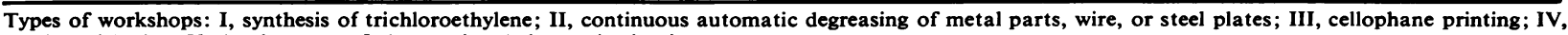
coating with glue; $\mathrm{V}$, development of photo-printed electronic circuit.

'Exposed daily, 8 hours a day, 6 days a week.

${ }^{2}$ Geometric means together with SD ranges in parentheses.

3TTC, TCE and TCA stand for measured values (mg/litre) of total trichloro-compounds, trichloroethanol and trichloroacetic acid, respectively.

-Total trichloro-compounds concentration (mg/litre) adjusted to a specific gravity of urine of 1.016.

${ }^{s}$ Total trichloro-compounds concentration divided by creatinine concentration $(\mathrm{mg} / \mathrm{g}$ creatinine).

Values previously reported (Ikeda and Ohtsuji, 1969b).

iNo measurable value. 


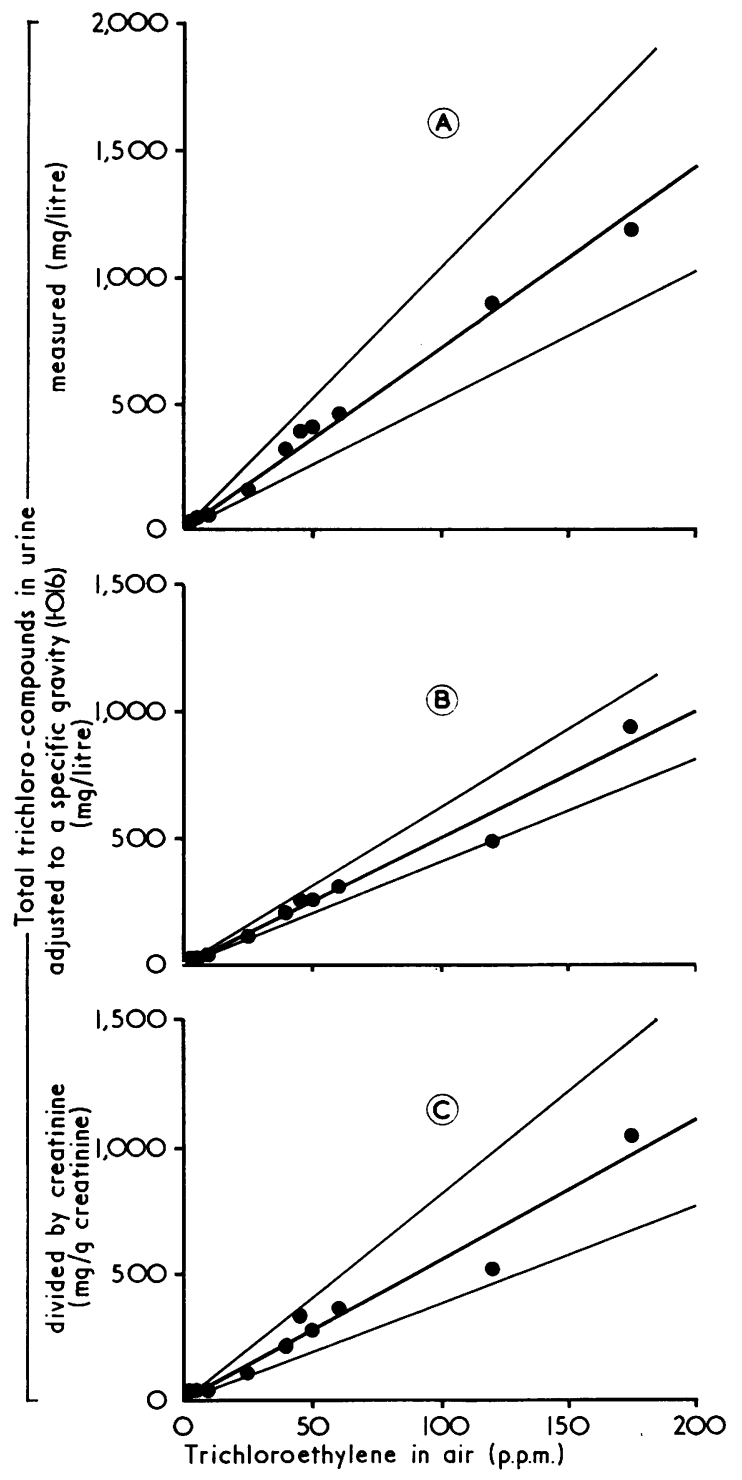

concentration exceeds 50 p.p.m. This relative decrease of the TCA level was further confirmed by the plotting of TCA concentration against that of TTC (Fig. 2). When the TTC concentration is greater than $500 \mathrm{mg} /$ litre (Fig. 2), which corresponds to a trichloroethylene concentration of 70 p.p.m. (Fig. $1 \mathrm{~A})$, the TCA concentration is no longer proportional to that of TTC in urine (Fig. 2) or trichloroethylene in air (Fig. 1E).

\section{Tetrachloroethylene exposure}

Figure 3 shows metabolite levels in the urine from the subjects exposed to tetrachloroethylene in
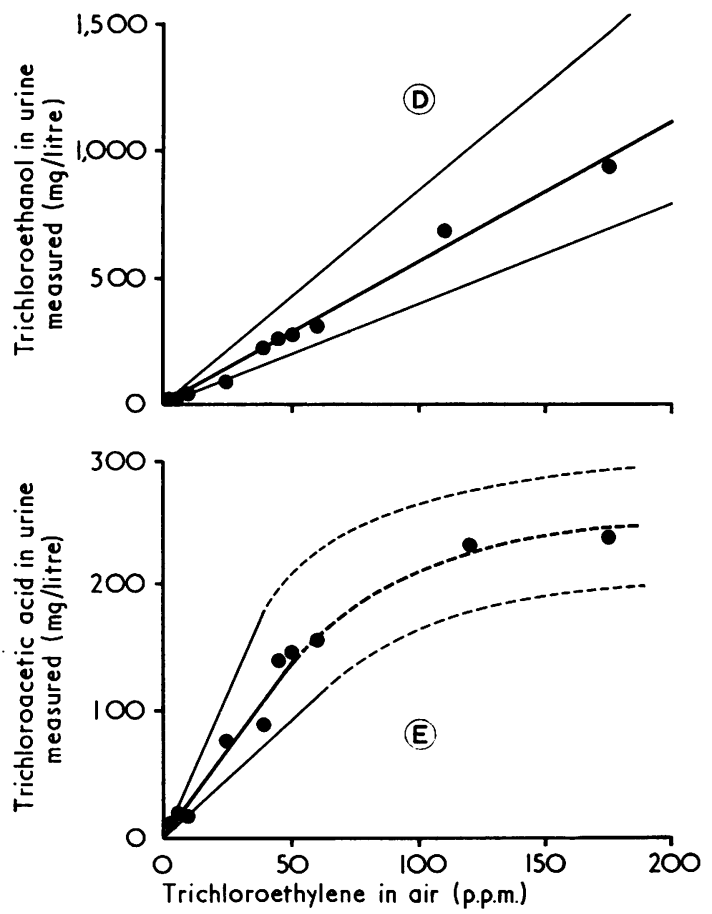

FIG. 1. Relation between atmospheric concentrations of trichloroethylene and metabolite concentrations in human urine: (A) total trichloro-compounds (measured value); (B) total trichloro-compounds (adjusted to a specific gravity of 1.016); (C) total trichloro-compounds (divided by creatinine concentration); (D) trichloroethanol (measured value); (E) trichloroacetic acid (measured value). The workers were exposed daily for 8 hours a day, 6 days a week. Each point represents a geometric mean of 4 to 9 urine samples as detailed in the Table. Lines in the figure are weighted calculated regression lines for the means ( - ) together with those for the SD ranges (-). In Fig. 1E, extrapolations $(--,,--\rightarrow)$ of the calculated regression lines $(-,-)$ in the trichloroethylene concentration of over 50 p.p.m. were drawn by eye.

relation to the concentration of tetrachloroethylene in the air. The workers were exposed daily for 8 hours a day, 6 days a week to tetrachloroethylene vapour whilst supervising automatic dip-washing machines (connected with ovens for drying off the solvent) used in the removal of a synthetic glue from kimono silk. (The glue was applied to prevent the undue blotting of the silk with dyes during the hand-painting Yuzen process.) As described in a previous paper (Ikeda and Ohtsuji, 1972), an increase was observed in coloration when the urine samples from tetrachloroethylene-exposed workers were oxidized before Fujiwara reaction. This increase is 


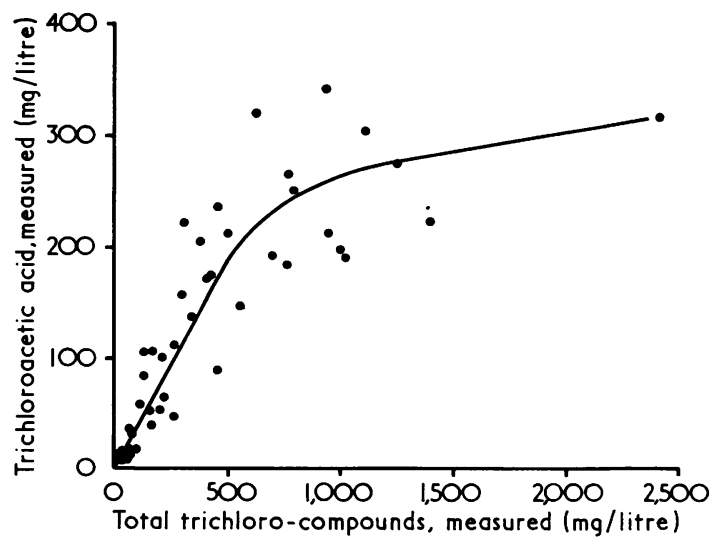

FIG. 2. Relation between concentrations of total trichloro-compounds and trichloroacetic acid in the urine of human subjects exposed to trichloroethylene. Individual data summarized in the Table together with other data were plotted. The curve in the figure was drawn by eye.

tentatively attributed to TCE. Despite wide variations in urinary metabolite levels, it is clear that both TCE and TCA levels, and consequently the TTC level, reach a plateau at concentrations well below 100 p.p.m. tetrachloroethylene. This finding was confirmed by the experimental exposure of rats to tetrachloroethylene (Fig. 4). No additional

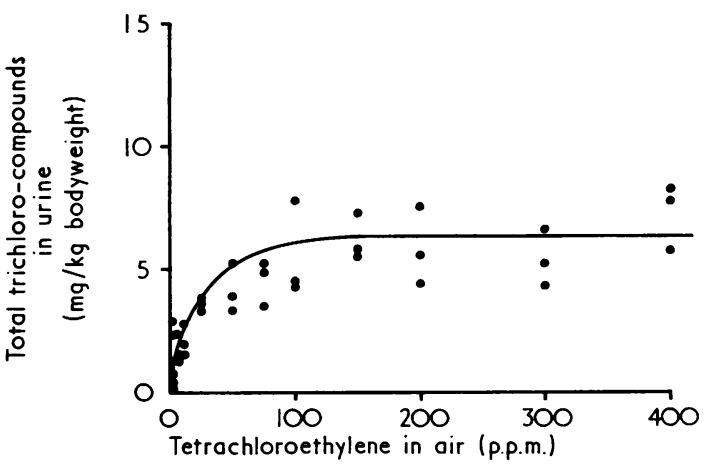

FIG. 4. Concentration of total trichloro-compounds in the urine of rats exposed to various concentrations of tetrachloroethylene. Female Wistar rats (weighing about $70 \mathrm{~g}$ ) were exposed to tetrachloroethylene vapour at the concentration indicated for 8 hours. Urine samples were collected (separately from faeces) for 48 hours after the beginning of the exposure.

Each symbol represents one urine sample pooled from a group of four rats. Metabolite excretion during the subsequent 48 -hour period was less than $10 \%$ of that excreted during the initial 48 hours. The curve was drawn by eye.
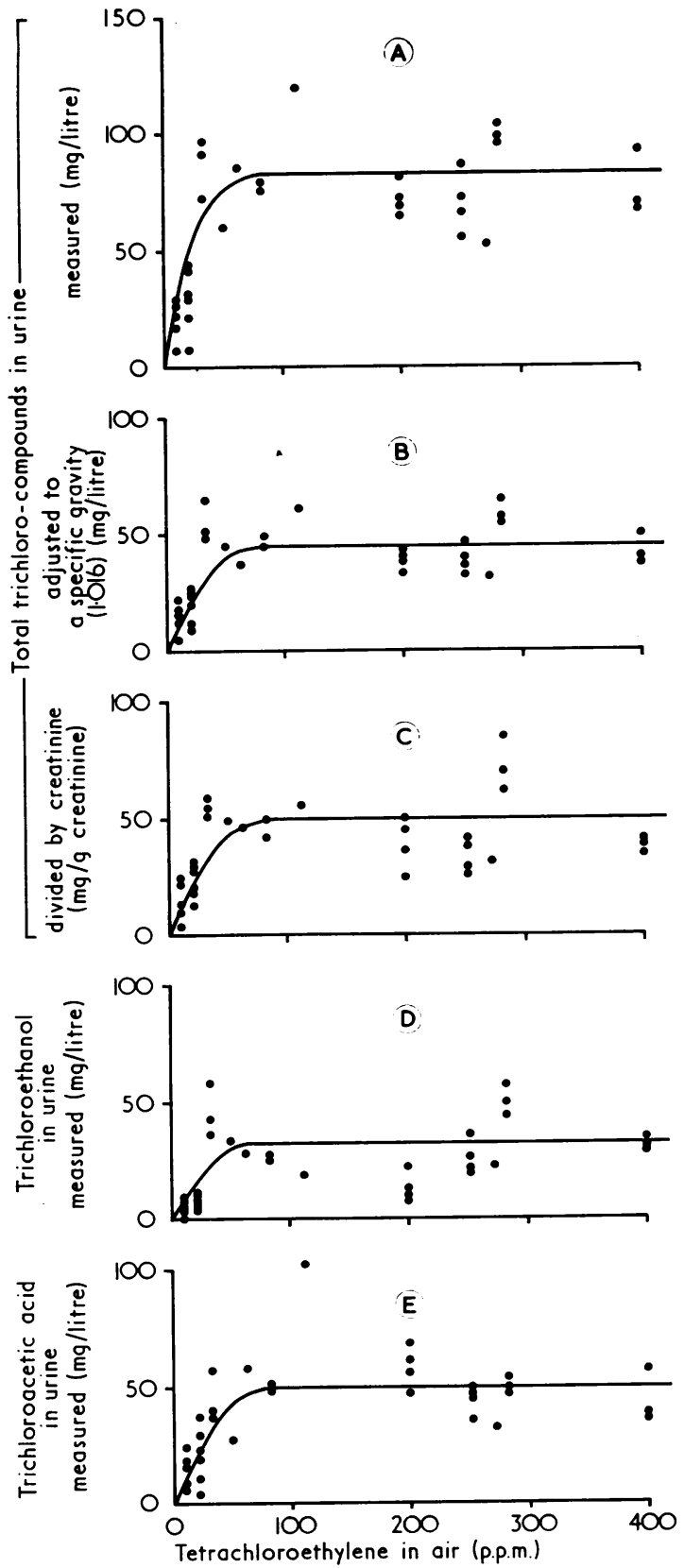

FIG. 3. Relation between atmospheric concentrations of tetrachloroethylene and metabolite concentrations in human urine: (A) total trichloro-compounds (measured value); (B) total trichloro-compounds (adjusted to a specific gravity of 1.016); (C) total trichloro-compounds (divided by creatinine concentration); (D) trichloroethanol (measured value); (E) trichloroacetic acid (measured value). Each symbol represents one urine sample from a worker. Curves were drawn by eye. 
increase was observed in the urinary metabolite levels with exposure to tetrachloroethylene of over 100 p.p.m., in contrast to results obtained with trichloroethylene where the concentration of urinary metabolites was related to the atmospheric concentration up to at least 200 p.p.m. (Tanaka and Ikeda, 1968).

\section{Discussion}

One of the difficulties in conducting balance studies of trichloroethylene and tetrachloroethylene is that experiments with limited repeated exposures cannot simulate occupational exposure. As trichloroethylene (Ikeda et al., 1971), and presumably tetrachloroethylene (Stewart et al., 1970a) also, has a long biological half-life, the urinary metabolite level increases gradually during repeated daily exposures (Stewart et al., 1970b). Even in the field survey, workshops using trichloroethylene (e.g., for degreasing) are not entirely suitable as the concentration of the solvent vapour in the air around the workers fluctuates sharply, depending both on the operation of the degreasing machines and on the distance between the workers and the solvent baths. To eliminate these difficulties, the only workshops surveyed were those where the machines (degreasers, rotary presses, etc.) were run automatically and continuously, where the location of the workers was fixed, and where the workshop-rooms were closed and rather small so that the vapour was evenly distributed throughout the room.

From the results shown in Fig. 1, it is possible to calculate the amount of trichloroethylene excreted in urine in the form of its metabolites. At a concentration of 100 p.p.m. trichloroethylene in the air, the estimated urinary excretion (Fig. 1A) is $730 \mathrm{mg}$ TTC/litre. Assuming that the rate of urine excretion is 50 to $100 \mathrm{ml} / \mathrm{hr}$, the equivalent amount of trichloroethylene excreted in urine is:

$730(\mathrm{mg} / \mathrm{l}.) \times \frac{131 \cdot 40}{163.40 \text { to } 149 \cdot 42} \times(0.05$ to 0.1$)(1 / \mathrm{hr})$

$\fallingdotseq 50(\mathrm{mg} / \mathrm{hr})$ where $131.40,163.40$, and $149 \cdot 42$ are molecular weights of trichloroethylene, TCA, and TCE, respectively. On the other hand, the amount of trichloroethylene absorbed through the lungs of workers in the atmosphere of 100 p.p.m. $\left(=535 \mathrm{mg} / \mathrm{m}^{3}\right)$ of trichloroethylene may be calculated on two assumptions; that the respiratory volume under the working condition is about 10 $1 / \mathrm{min}$, and that the retention of inhaled trichloroethylene is about $50 \%$ (about $35 \%$ according to Nomiyama and Nomiyama (1971); about $63 \%$ according to Stewart et al. (1970b). Thus the amount absorbed is:

$$
535\left(\mathrm{mg} / \mathrm{m}^{3}\right) \times 10 \times 10^{-3}\left(\mathrm{~m}^{3} / \mathrm{min}\right) \times 60 \times 0.5
$$
$\fallingdotseq 160(\mathrm{mg} / \mathrm{hr})$.
Such being the case, only one-third of the absorbed trichloroethylene is excreted in urine during the work period. This low rate of urinary excretion agrees with previous observations which reported accumulation in the body during exposure (Browning, 1965) and long-term excretion of metabolites after cessation of exposure with a biological half-life of about 40 hours (calculated by the present authors from the results given by Stewart et al., 1970b) to 95 hours (Ikeda et al., 1971), even if a portion of trichloroethylene retained may also be excreted in alveolar breath (Stewart et al., 1970b). The relative decrease in the rate of TCA excretion above concentrations of 50 p.p.m. trichloroethylene (Fig. 1E) may be of toxicological importance as the other metabolite, TCE, is much more neuro- and cardiotoxic than trichloroethylene (Mikisková and Mikiska, 1966). It is possible that the prevalence of subjective symptoms in trichloroethylene poisoning is related to this change in the pattern of metabolism.

Although a quantitative evaluation of workers' complaints was not made, the impressions gained during the present survey agree with Takamatsu's (1962) observation as well as that of Bardoděj and Vyskočil (1956) that the incidence of subjective symptoms, mainly of the nervous system, was greater when the atmospheric concentration of trichloroethylene was higher than 50 p.p.m., while no apparent ill effects were observed at lower concentrations.

Urine analysis for metabolites appears to be of less value in estimating exposure to tetrachloroethylene as the TTC level is no longer proportional to environmental tetrachloroethylene vapour, even at the low concentration of 100 p.p.m., and the results are also more variable (Fig. 3). It is stressed, however, that this plateau formation suggests that the capacity of human subjects to metabolize tetrachloroethylene is limited, even at relatively low concentrations. As discussed in the preceding paper (Ikeda and Ohtsuji, 1972), tetrachloroethylene appears (when compared with trichloroethylene) to be less susceptible to undergo biotransformation, and in addition its excretion through the lungs is slower.

These changes in the metabolism pattern found in both trichloroethylene and tetrachloroethylene could imply the necessity to reduce the TLV of the two solvents from the present value of 100 p.p.m. for both compounds (the values recommended by the Japanese Society of Industrial Medicine and the American Conference of Governmental Industrial Hygienists in 1970).

The interest and support of Professor M. Nishio (Kyoto University, Kyoto) are gratefully acknowledged. Thanks arealso due to Dr. M. Suzumura (Toagosei Chemical Co., Nagoya Plant, Nagoya) and S. Miyahara (Kyoto Labour Standard Bureau, Kyoto) for their co-operation in 
collecting urine samples, and M. O'Halloran for reviewing the manuscript. This work was supported in part by a grant from the Japanese Ministry of Education to one of us (M.I.) and by a grant from the Fujiwara Memorial Fund.

A part of this paper was presented at the 44 th Annual Meeting of the Japanese Society of Industrial Medicine in Tokyo on 3-4 April, 1971.

\section{References}

Bardoděj, E., and Vyskočil, J. (1956). The problems of trichloroethylene in occupational medicine. Arch. industr. Hlth, 13, 581-592.

Bartonicěk, V. (1962). Metabolism and excretion of trichloroethylene after inhalation by human subjects. Brit. J. industr. Med., 19, 134-141.

Browning, E. (1965). Toxicity amd Metabolism of Industrial Solvents, pp. 189-212. Elsevier, Amsterdam and London.

Byington, K. H., and Leibman, K. C. (1965). Metabolism of trichloroethylene in liver microsomes. II. Identification of the reaction product as chloral hydrate. Molec. Pharmacol., 1, 247-254.

Cooper, J. R., and Friedman, P. J. (1958). The enzymic oxidation of chloral hydrate to trichloroacetic acid. Biochem. Pharmacol., 1, 76-82.

Daniel, J. W. (1963). The metabolism of ${ }^{36} \mathrm{Cl}$-labelled trichloroethylene and tetrachloroethylene in the rat. Biochem. Pharmacol., 12, 795-802.

Friedman, P. J., and Cooper, J. R. (1960). The role of alcohol dehydrogenase in the metabolism of chloral hydrate. J. Pharmacol. exp. Ther., 129, 373-376.

Heath, D. F. (1967). Normal or log-normal: Appropriate distributions. Nature (Lond.), 213, 1159-1160.

Ikeda, M., and Ohtsuji, H. (1969a). Significanceof urinary hippuric acid determination as an index of toluene exposure. Brit. J. industr. Med., 26, 244-246.

, $(1969 \mathrm{~b})$. Hippuric acid, phenol and trichloroacetic acid levels in the urine of Japanese subjects with no known exposure to organic solvents. Brit.J. industr. Med., 26, 162-164.

- 1 (1972). A comparative study on the excretion of Fujiwara reaction-positive substances in the urine of humans and rodents given trichloro- or tetrachloroderivatives of ethane and ethylene. Brit. J. industr. Med., 29, 94-104.
Kawai, H., and Kuniyoshi, M. (1971). Excretion kinetics of urinary metabolites in a patient addicted to trichloroethylene. Brit. J. industr. Med., 28, 203-206.

Jackson, S. (1966). Creatinine in urine as an index of urinary excretion rate. Hlth Phys., 12, 843-850.

Kitagawa, T. (1961). The rapid measurement of toxic gases and vapour. In Proc. 13th int. Congr. occup. Hlth, New York, 1960, pp. 506-512.

Malchy, H., and Parkhouse, J. (1969). Respiratory studies with trichloroethylene. Canad. Anaesth. Soc. J., 16, 119-134.

Mikisková, H., and Mikiska, A. (1966). Trichloroethanol in trichloroethylene poisoning. Brit. J. industr. Med., 23, 116-125.

Nomiyama, K., and Nomiyama, H. (1971). Metabolism of trichloroethylene in humans: sex difference in urinary excretion of trichloroacetic acid and trichloroethanol. Int. Arch. Arbeitsmed., 28, 37-48.

Parkhouse, J. (1969). Uptake and metabolism of trichloroethylene. Canad. anaesth. Soc. J., 16, 113-118.

Rainsford, S. G., and Lloyd Davies, T. A. (1965). Urinary excretion of phenol by men exposed to vapour of benzene: a screening test. Brit. J. industr. Med., 22, 21-26.

Smith, G. F. (1966). Trichlorethylene: a review. Brit. J. industr. Med., 23, 249-262.

Snedecor, G. W. (1956). Statistical Methods, 5th ed. Iowa State University Press, Ames, Iowa.

Soucěk, B., and Vlachová, D. (1960). Excretion of trichloroethylene metabolites in human urine. Brit.J. industr. Med., 17, 60-64.

Stewart, R. D., Baretta, E. D., Dodd, H. C., and Torkelson, T. R. (1970a). Experimental human exposure to tetrachloroethylene. Arch. environm. Hlth, 20, 224-229.

, Dodd, H. C., Gay, H. H., and Erley, D. S. (1970b). Experimental human exposure to trichloroethylene. Arch. environm. Hlth, 20, 64-71.

Takamatsu, M. (1962). Health hazards in workers exposed to trichloroethylene vapor. Kumamoto med. J., 15, 43-54.

Tanaka, S., and Ikeda, M. (1968). A method for determination of trichloroethanol and trichloroacetic acid in urine. Brit. J. industr. Med., 25, 214-219.

Yllner, S. (1961). Urinary metabolites of ${ }^{14} \mathrm{C}$-tetrachloroethylene in mice. Nature (Lond.), 191, 820.

Received for publication July 16, 1971. 